\title{
Integration of phase change material into fiber cement roof for reduction of heat accumulation in buildings
}

\author{
Atthakorn Thongtha, Ketwadee Janyoosuk, Chanita Mano* \\ Department of Physics, Faculty of Science, Naresuan University, Phitsanulok 65000 Thailand \\ *Corresponding author, e-mail: chanita.mano@gmail.com
}

Received 10 Nov 2020

Accepted 30 May 2021

\begin{abstract}
This research focuses on the application of phase change material (PCM) combined with the fiber cement roofing sheet to reduce heat transfer through the building. The experimental study was divided into 4 conditions including the single-layer fiber cement roof (SF), the single-layer fiber cement roof installed with the PCM layer (SFPCM), the double-layer fiber cement roof (DF), and the double-layer fiber cement roof installed with the PCM layer (DF-PCM). For each condition, the fiber cement sheet was set at an incline angle of $40^{\circ}$ with the horizontal plane. The thermal source was controlled at temperature of $60^{\circ} \mathrm{C}, 70^{\circ} \mathrm{C}$ and $80^{\circ} \mathrm{C}$ for 360 min to investigate the thermal behavior and compare the heat gain through the roof. The results showed that the DF-PCM could reduce the room temperature by up to $3.1 \%, 3.8 \%$ and $3.7 \%$ when compared with the SF, and up to $5.6 \%, 5.2 \%$ and $4.8 \%$ when compared with the $\mathrm{DF}$ at the controlled heat source temperature of approximately $60^{\circ} \mathrm{C}, 70^{\circ} \mathrm{C}$ and $80^{\circ} \mathrm{C}$, respectively. It indicated that the use of PCM integrated into the fiber cement roofing sheet could reduce the heat transfer and interior room temperature, leading to energy saving.
\end{abstract}

KEYWORDS: phase change material, fiber cement sheet roofing, energy saving, heat transfer reduction, heat accumulation decrement

\section{INTRODUCTION}

Energy consumption in the building sector continually rises over the past decade, due to the rapid growth of urbanization, the population growth, more time spent indoors, and more requirement for the living indoors quality, etc. [1]. Building energy consumption currently accounts for a significant part of the total global energy consumption. However, the important energy saving can be achieved from the optimal design of developed buildings [2]. In the tropical area, the climate is hot and high solar radiation intensity all year-round leads to heat accumulation in the buildings [3]. Most of the tropical energy consumption in the buildings is used to keep an indoor thermal comfort through air-conditioning system [4]. Therefore, an improvement of thermal insulation properties of building envelope is a guideline for reducing the heat accumulation in buildings, which can decrease the energy consumption from the cooling load of the air conditioner, as well as enhancing annual energy saving [5]. Nevertheless, the heat transmissibility into building roof accounts for a major proportion of the daily heat transfer to indoor space [6], so the design and material selection of the roof are essential to reduce the indoor temperature and thermal accumulation [7]. Materials roofing like metal sheets, asbestos cement sheets and corrugated fiber cement sheets are abundantly used in tropical regions. The metal sheet roofs in tropical countries have disadvantages in a sense that they provide a poor indoor thermal environment and make a lot of noise during rainfall [8]. While, the fiber cement sheets are considered a material suited for roofing due to their functions such as sound insulation, nonflammability, good drainage, strength, durability and affordable prices [9]. Consequently, the fiber cement sheet roof is appropriate to be applied for reducing heat gain in tropical buildings [10].

Recently, PCMs as thermal storage materials has extensively grown due to absorbing and releasing heat energy during liquefaction and solidification at their phase change temperatures which is able to be used for maintaining the constant temperature [11]. From previous literatures, the use of PCMs in building envelopes, such as walls $[11,12]$, windows $[13,14]$ and especially in roofs [15-19], can reduce energy demands and improve indoor thermal comfort [11]. Guichard et al [15] could reduce the indoor space temperature by $2.4^{\circ} \mathrm{C}$ and decrease the daily fluctuation when PCM layers 
were integrated with the corrugated metal roofs. Chung and Park [11] reported the increase in the indoor thermal comfort by putting the PCMs plates into the building roofs. The indoor heat gain by around between $12.1 \%$ and $17.3 \%$ when adding PCMs into vertical cylindrical holes at concrete roof was also reported [20]. Meng et al [6] improved the heat performance of a building roof by using a PCM layer and a high reflective film, which can decrease inner surface roof temperature and the heat flux by approximately $2.2^{\circ} \mathrm{C}$ and $66.8 \%$ when compared to the roof without PCM layer and the high reflective film. Chou et al [21] introduced a double layer metal sheet roof integrating the PCM layer which improved better thermal insulation properties of building roof.

To reduce thermal gain and heat transfer into the interior space of the buildings, PCM as paraffin was integrated into the fiber cement sheets roof in this study. The four testing models comprised SF, SF-PCM, DF, and DF-PCM were designed with focus on the thermal behavior to obtain an inertia heat gain reduction and a conservation of energy consumption in buildings.

\section{MATERIALS AND METHODS}

\section{PCM analysis and encapsulation}

The melting range of phase change temperature is one of the significant factors for PCM application into the building envelopes because it affects efficiency in thermal storage. The thermal process characteristics of PCM were measured by Differential Scanning Calorimetry (DSC) technique at the temperature range from $0{ }^{\circ} \mathrm{C}$ to $80^{\circ} \mathrm{C}$ and the heat rate of $0.05^{\circ} \mathrm{C} / \mathrm{min}$. The PCM used was a paraffin type encapsulated by polyethylene (PE) bag of the size $30.50 \mathrm{~cm} \times 46.00 \mathrm{~cm}$. Each PE bag contains PCM of approximately $5 \mathrm{~g}$ with thickness of $2.15 \mathrm{~cm}$, these were arranged between two reflective plates to form a PCM layer with the area of $100 \mathrm{~cm} \times 100 \mathrm{~cm}$, as demonstrated in Fig. S1. The actual experimental setup for PCM application with the fiber cement sheet is shown in Fig. S2.

\section{Experimental set-up}

PCM was applied into the fiber cement sheet roof, Fig. 1a shows the dimensions of the testing model and the installation position of the heat source, these testing models were $1 \mathrm{~m} \times 1 \mathrm{~m} \times 1 \mathrm{~m}$ rooms in dimension. The walls and floors were built from the plywood sheets with a thickness of $1 \mathrm{~cm}$ and the inside walls were insulated by polyethylene sheets with a thickness of $0.1 \mathrm{~mm}$ to prevent heat transfer through these parts. The gypsum board with a thickness of $0.5 \mathrm{~cm}$ and an area size of $1 \mathrm{~m} \times 1 \mathrm{~m}$ was used as the ceiling. For the roof part of these testing models, the fiber cement sheets $(1 \mathrm{~m} \times 1 \mathrm{~m})$ with a thickness of $0.5 \mathrm{~cm}$ were placed at a horizontal angle of 40 degrees for roofing. The models in this study were divided into four types, consisting of SF and SF-PCM (Fig. 1bc), and the DF and DFPCM (Fig. 1de). The four models were constantly tested at the controlled temperatures of $60^{\circ} \mathrm{C}, 70^{\circ} \mathrm{C}$ and $80^{\circ} \mathrm{C}$. A thermal source is an electric hot plate, installed approximately $15 \mathrm{~cm}$ above the upstairs roof and was controlled by using a voltage dimmer. The exterior surface temperature of upstairs roof $\left(\mathrm{T}_{\mathrm{OR}-\mathrm{UP}}\right)$, the inside surface temperature of upstairs roof $\left(\mathrm{T}_{\mathrm{IR}-\mathrm{UP}}\right)$, the PCM layer temperature $\left(\mathrm{T}_{\mathrm{PCM}}\right)$, the space temperature between the roofing sheets $\left(T_{A R}\right)$, the upper surface temperature of downstairs roof $\left(\mathrm{T}_{\mathrm{OR}-\mathrm{D}}\right)$, the lower surface temperature of downstairs roof $\left(\mathrm{T}_{\mathrm{IR}-\mathrm{D}}\right)$, the space temperature of attic $\left(\mathrm{T}_{\mathrm{AA}}\right)$, the upper ceiling surface temperature $\left(\mathrm{T}_{\mathrm{UC}}\right)$, the lower ceiling surface temperature $\left(\mathrm{T}_{\mathrm{LC}}\right)$, the inside testing room temperature $\left(\mathrm{T}_{\text {Room }}\right)$ and the ambient temperature $\left(\mathrm{T}_{\mathrm{AM}}\right)$ were measured using the K-type thermocouples with an accuracy of approximately $\pm 0.5^{\circ} \mathrm{C}$ as demonstrated in Fig. 1b-e. The ambient temperature was controlled at approximately $25^{\circ} \mathrm{C}$ by an air conditioner. The temperature at each location was measured in 5 min intervals and recorded continuously for $360 \mathrm{~min}$ using a data logger to study the thermal behavior of each testing models roof.

\section{RESULTS AND DISCUSSION}

\section{Thermal analysis of PCM}

It has been reported that the range of phase change temperature of PCM is an important factor in the selection of a PCM to apply with building envelope for decreasing of cooling load in buildings $[2,11,20]$. The phase change temperature range of PCM should be lower than the temperature of the building envelope [2]. In this work, the thermal characteristics of paraffin as a PCM were investigated by DSC under the temperature range from $0^{\circ} \mathrm{C}$ to $80^{\circ} \mathrm{C}$. The result shows two curves of heat flow against temperature, an endothermic reaction curve represented by negative peak and an exothermic reaction curve represented by positive peak (Fig. 2). From $0{ }^{\circ} \mathrm{C}$ to $80^{\circ} \mathrm{C}$, the two negative peaks appeared in the endothermic reaction curve. The first endothermic peak with a latent heat of 


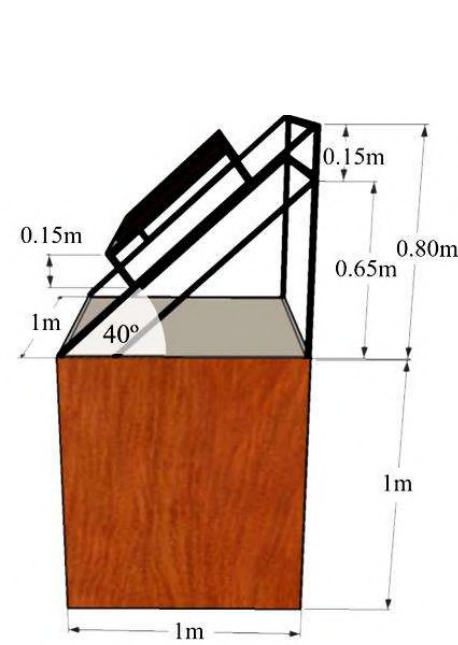

(a)

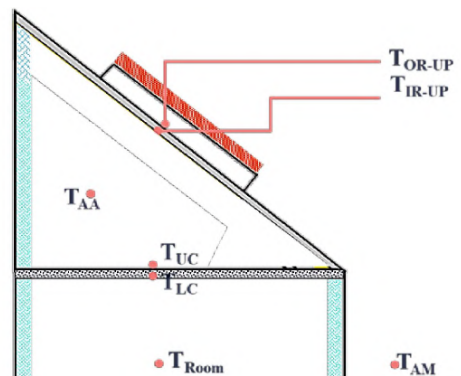

(b)

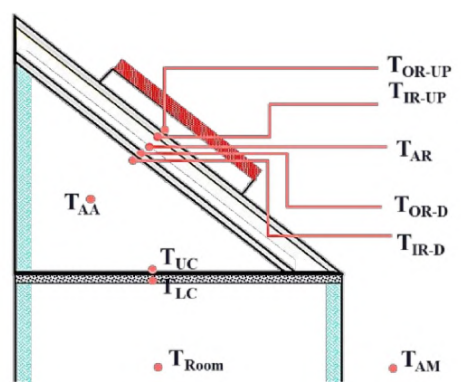

(d)

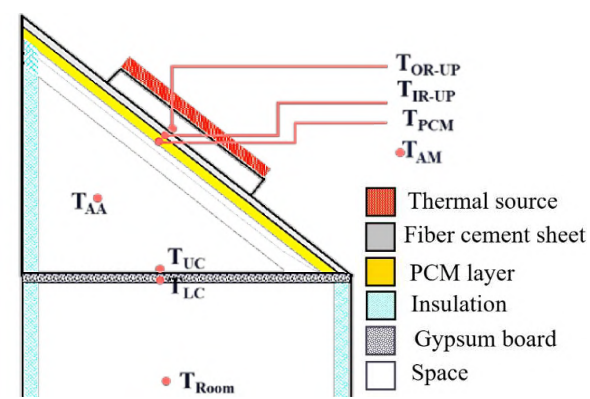

(c)

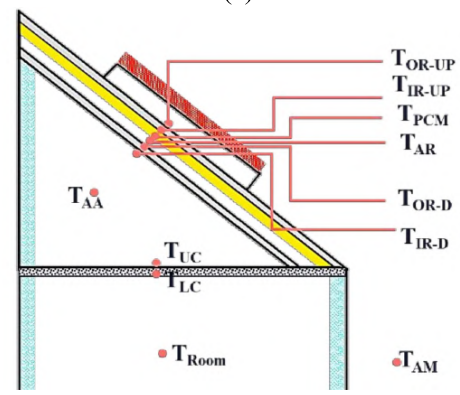

(e)

Fig. 1 (a) The dimensions of the testing models, the positions of the fixed thermocouples in the SF; (b) without and (c) with the PCM layer, and the positions of the fixed thermocouples in the DF; (d) without and (e) the PCM layer.

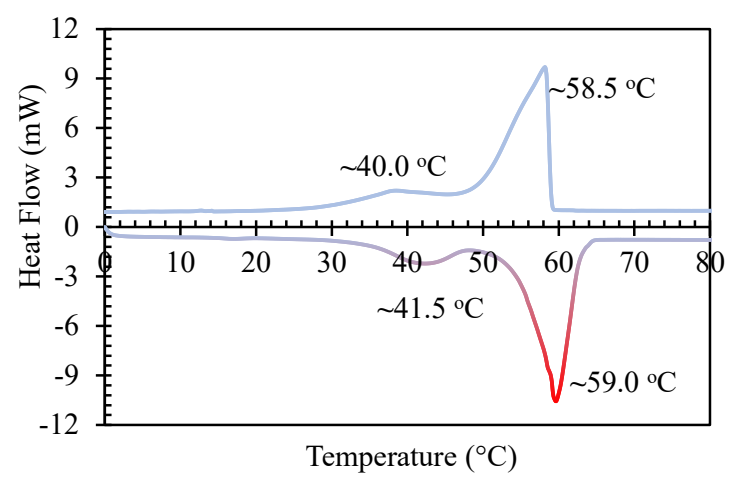

Fig. 2 DSC results showing the thermal behavior of PCM.

$22.13 \mathrm{~J} / \mathrm{g}$ was observed at around $41.5^{\circ} \mathrm{C}$ relating to the starting of the melting process of paraffin. While another endothermic peak appeared at a temperature around $59.0^{\circ} \mathrm{C}$ with a latent heat of $137.67 \mathrm{~J} / \mathrm{g}$ corresponding to the thermal absorption during the process of phase transition to a liquid state of paraffin, which was continued from the first peak. When reducing the temperature from $80^{\circ} \mathrm{C}$ to $0^{\circ} \mathrm{C}$, the two exothermic reaction peaks were observed. The first exothermic peak with a latent heat of $131.35 \mathrm{~J} / \mathrm{g}$ was achieved at approximately $58.5^{\circ} \mathrm{C}$ and a second small exothermic peak was observed at approximately $40.0^{\circ} \mathrm{C}$ with a latent heat of $11.25 \mathrm{~J} / \mathrm{g}$, these were related to the thermal release of paraffin during the solidification process. This suggests that the situation of melting and solidification temperature range of this paraffin-type PCM was appropriate for PCM application to reduce the indoor temperature and thermal transmission through the roof because the temperature range of this PCM is lower than the roof temperature in tropical area (around $70.0^{\circ} \mathrm{C}$ or higher during hot days) [3].

\section{Thermal behavior of different testing models \\ Average temperatures at different positions of each testing model}

When the thermal source constantly controlled the temperature of $60^{\circ} \mathrm{C}$, all the temperatures: $\mathrm{T}_{\mathrm{OR}-\mathrm{UP}}$, $\mathrm{T}_{\mathrm{IR}-\mathrm{UP}}, \mathrm{T}_{\mathrm{PCM}}, \mathrm{T}_{\mathrm{AR}}, \mathrm{T}_{\mathrm{OR}-\mathrm{D}}, \mathrm{T}_{\mathrm{IR}-\mathrm{D}}, \mathrm{T}_{\mathrm{AA}}, \mathrm{T}_{\mathrm{UC}}, \mathrm{T}_{\mathrm{LC}}, \mathrm{T}_{\text {Room }}$ and $\mathrm{T}_{\mathrm{AM}}$ of the four testing models were measured and recorded in 5 min intervals for $360 \mathrm{~min}$ using a data logger, as shown in Fig. 3. The ambient temperature $\mathrm{T}_{\mathrm{AM}}$ was steadily set at temperature of around $25^{\circ} \mathrm{C}$ which was controlled by an air conditioner. The temperature in each position of each model was gradually increased from the $\mathrm{T}_{\mathrm{AM}}$ until the temperature was stable. After the temperature in each position was steady, the temperature values 

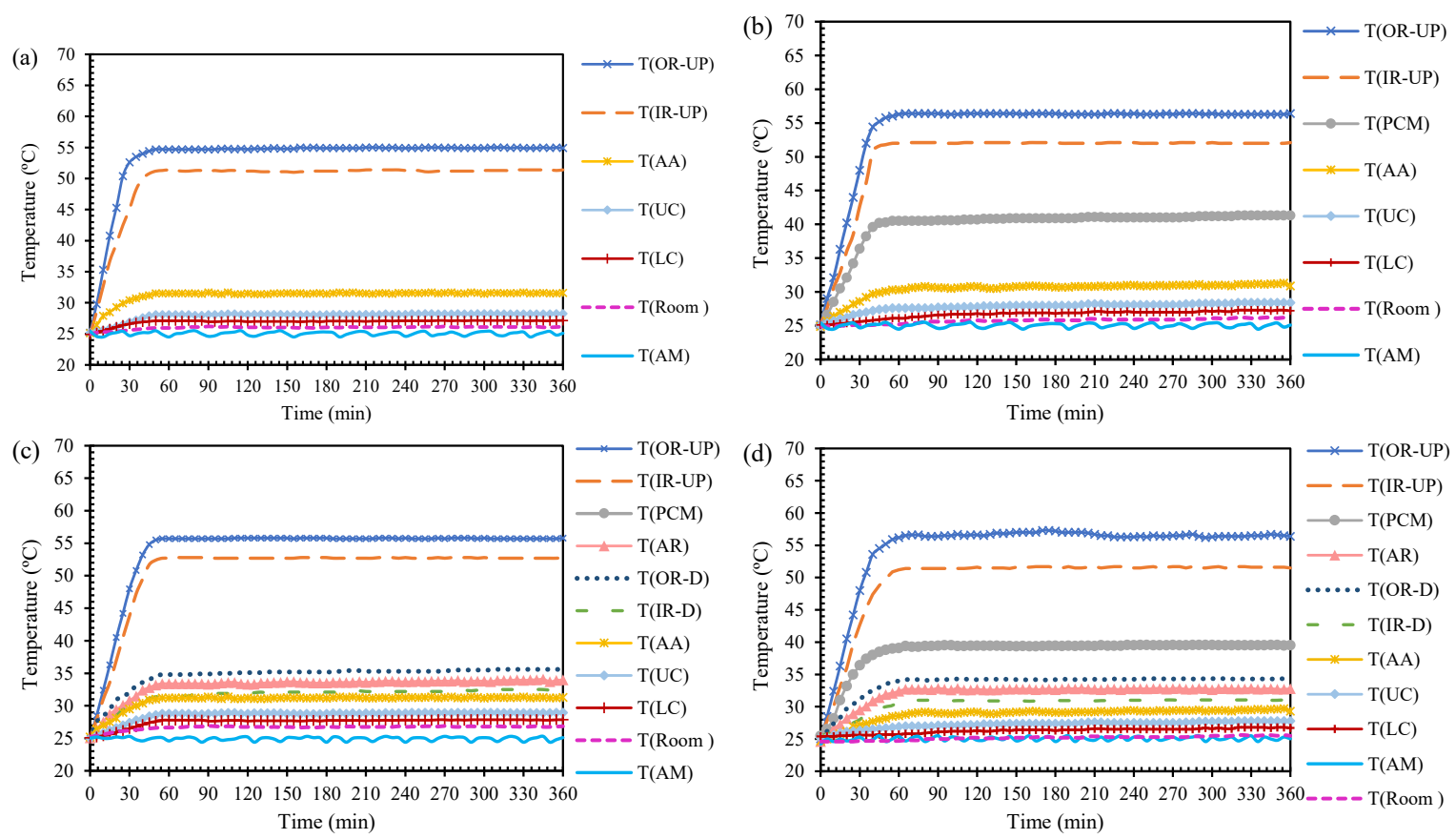

Fig. 3 Temperature variation at each position under temperature-controlled at $60^{\circ} \mathrm{C}$ of (a) SF, (b) SF-PCM, (c) DF, (d) DF-PCM roof models.

Table 1 Average temperatures at the $\mathrm{T}_{\mathrm{OR}-\mathrm{UP}}, \mathrm{T}_{\mathrm{IR}-\mathrm{UP}}, \mathrm{T}_{\mathrm{AA}}, \mathrm{T}_{\mathrm{UC}}, \mathrm{T}_{\mathrm{LC}}, \mathrm{T}_{\mathrm{Room}}$ and $\mathrm{T}_{\mathrm{AM}}$ under different controlled temperature conditions.

\begin{tabular}{|c|c|c|c|c|c|c|c|c|c|c|c|c|}
\hline $\mathrm{T}$ (control) & Model & $\mathrm{T}_{\mathrm{OR}-\mathrm{UP}}$ & $\mathrm{T}_{\text {IR-UP }}$ & $\mathrm{T}_{\mathrm{PCM}}$ & $\mathrm{T}_{\mathrm{AR}}$ & $\mathrm{T}_{\mathrm{OR}-\mathrm{D}}$ & $\mathrm{T}_{\mathrm{IR}-\mathrm{D}}$ & $\mathrm{T}_{\mathrm{AA}}$ & $\mathrm{T}_{\mathrm{UC}}$ & $\mathrm{T}_{\mathrm{LC}}$ & $\mathrm{T}_{\text {Room }}$ & $\mathrm{T}_{\mathrm{AM}}$ \\
\hline \multirow[t]{4}{*}{$60^{\circ} \mathrm{C}$} & SF & 54.9 & 51.3 & - & - & - & - & 31.5 & 28.2 & 27.1 & 26.1 & 25.1 \\
\hline & SF-PCM & 56.4 & 52.1 & 40.9 & - & - & - & 30.8 & 28.0 & 26.9 & 25.9 & 25.1 \\
\hline & DF & 55.7 & 52.7 & - & 33.7 & 35.3 & 32.1 & 31.2 & 28.9 & 27.8 & 26.8 & 24.9 \\
\hline & DF-PCM & 56.6 & 51.6 & 39.5 & 32.7 & 34.3 & 31.0 & 29.3 & 27.5 & 26.4 & 25.3 & 25.0 \\
\hline \multirow[t]{4}{*}{$70^{\circ} \mathrm{C}$} & SF & 59.5 & 55.8 & - & - & - & - & 32.0 & 28.9 & 27.7 & 26.6 & 24.9 \\
\hline & SF-PCM & 61.3 & 56.7 & 44.9 & - & - & - & 31.3 & 28.5 & 27.2 & 26.1 & 25.2 \\
\hline & DF & 60.5 & 57.1 & - & 36.5 & 38.0 & 34.9 & 31.6 & 29.2 & 28.0 & 26.9 & 25.1 \\
\hline & DF-PCM & 61.5 & 56.3 & 43.9 & 35.6 & 37.2 & 34.0 & 29.5 & 27.9 & 26.7 & 25.5 & 25.2 \\
\hline \multirow[t]{4}{*}{$80^{\circ} \mathrm{C}$} & SF & 64.7 & 60.6 & - & - & - & - & 32.4 & 29.2 & 28.0 & 26.8 & 25.1 \\
\hline & SF-PCM & 66.7 & 61.7 & 49.5 & - & - & - & 31.8 & 29.0 & 27.7 & 26.6 & 25.1 \\
\hline & DF & 65.7 & 62.1 & - & 37.8 & 39.4 & 36.2 & 31.9 & 29.5 & 28.4 & 27.1 & 25.0 \\
\hline & DF-PCM & 66.9 & 61.3 & 48.5 & 37.0 & 38.8 & 35.2 & 30.2 & 28.4 & 27.0 & 25.8 & 25.1 \\
\hline
\end{tabular}

were calculated to achieve the average value of each location (Table 1). The temperature variation in the case of SF is displayed in Fig. 3a. Average values for $\mathrm{T}_{\mathrm{OR}-\mathrm{UP}}, \mathrm{T}_{\mathrm{IR}-\mathrm{UP}}, \mathrm{T}_{\mathrm{AA}}, \mathrm{T}_{\mathrm{UC}}, \mathrm{T}_{\mathrm{LC}}$ and $\mathrm{T}_{\text {Room }}$ were at around $54.9^{\circ} \mathrm{C}, 51.3^{\circ} \mathrm{C}, 31.5^{\circ} \mathrm{C}, 28.2^{\circ} \mathrm{C}, 27.1^{\circ} \mathrm{C}$ and $26.1^{\circ} \mathrm{C}$, respectively (Table 1 ). The temperature variation in each position of the SF-PCM, DF and DF-PCM had the same trend with that of the SF as demonstrated in Fig. 3b-d. This illustrates that the temperature variation of testing with controlled temperature was different from the testing with actual weather, which varies with the weather of the day $[11,15]$. When the controlled temperature of the heat source was increased from $60^{\circ} \mathrm{C}$ to $70^{\circ} \mathrm{C}$ and $80^{\circ} \mathrm{C}$, an average temperature in each position of all models increased (Table 1).

\section{The temperature difference $(\Delta T)$}

$\mathrm{T}_{\mathrm{OR}-\mathrm{UP}}$ and $\mathrm{T}_{\text {Room }}$ of each testing model under different controlled temperatures were listed in Table 1. The temperature difference $(\Delta \mathrm{T})$ between the exterior surface and the center of inside room was 

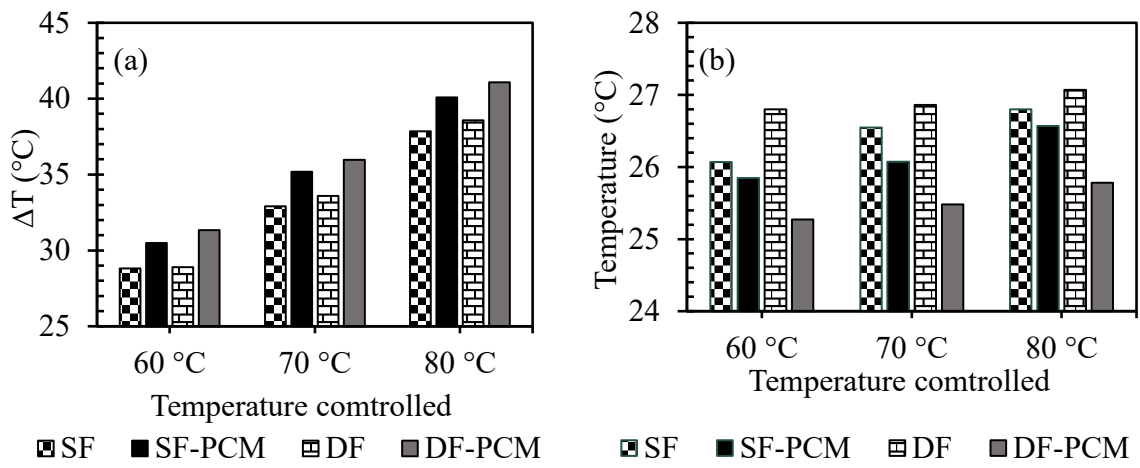

Fig. 4 Comparison of each temperature-controlled condition: (a) Temperature difference $(\Delta \mathrm{T})$ between the exterior roof surface temperature and room temperature and (b) the average inside room temperature $\left(\mathrm{T}_{\text {Room }}\right)$.

as shown (Fig. 4a). For the controlled temperature of $60^{\circ} \mathrm{C}$, the temperature differences of the models without and with the PCM installation in a single roof layer and double roof layers were around $28.8^{\circ} \mathrm{C}, 30.5^{\circ} \mathrm{C}, 28.9^{\circ} \mathrm{C}$, and $31.3^{\circ} \mathrm{C}$, respectively. In the case of $\mathrm{SF}, \Delta \mathrm{T}$ increased from $28.8^{\circ} \mathrm{C}$ to $37.8^{\circ} \mathrm{C}$ when controlled temperature of thermal source increased from $60^{\circ} \mathrm{C}$ to $80^{\circ} \mathrm{C}$. For SF-PCM, DF, and DF-PCM, the temperature difference trends were similar to that of the SF (Fig. 4a). Higher temperature difference was achieved in the model integrating PCM layer which indicated an effectiveness of heat flow reduction through the fibercement roof sheets and an achievement of indoor heat accumulation declination $[2,15]$. This leads to the conservation of energy consumption in buildings $[6,7]$.

\section{Average inside room temperature}

The average inside room temperature $\mathrm{T}_{\text {Room }}$ of each model under different controlled-temperature is demonstrated in Table 1 and Fig. 4b. With the controlled temperature of $60^{\circ} \mathrm{C}$, the average $\mathrm{T}_{\text {Room }}$ of both single layered and double layered roofs were decreased by installing the PCM layer with the fibercement roof sheets. The average $\mathrm{T}_{\text {Room }}$ values of SF, SF-PCM, DF, and DF-PCM were approximately $26.1^{\circ} \mathrm{C}, 25.9^{\circ} \mathrm{C}, 26.8^{\circ} \mathrm{C}$ and $25.3^{\circ} \mathrm{C}$, respectively. The lowest average $\mathrm{T}_{\text {Room }}$ was found with the DFPCM. The $\mathrm{T}_{\text {Room }}$ of this model was lower by approximately $3.1 \%, 2.3 \%$ and $5.6 \%$ when compared to SF, SF-PCM, and DF.

For the SF model, the average $\mathrm{T}_{\text {Room }}$ reached around $26.6^{\circ} \mathrm{C}$ and $26.8^{\circ} \mathrm{C}$ when the controlled temperature was increased to $70^{\circ} \mathrm{C}$ and $80^{\circ} \mathrm{C}$, respectively. The average $\mathrm{T}_{\text {Room }}$ of other models showed an increasing trend similar to that of the SF
(Fig. 4b). The SF-PCM and DF-PCM could decrease the average $\mathrm{T}_{\text {Room }}$ when compared to the testing models without PCM installed in each temperaturecontrolled condition. This demonstrated that the integrating PCM with the SF and DF could reduce the heat transfer from the roof and indoor heat gain resulting in a reduction of the building energy consumption and the annual peak cooling requirement $[7,15,20]$.

\section{Thermal resistance of each testing model}

The thermal resistance is one of the most important factors when considering the roofing materials, which affects the efficiency in preventing thermal propagation from the outside areas through the roof into the interior space of buildings $[2,7,11]$. The thermal resistance (R-value) indicates the resistance of heat flow through building envelope material into inside buildings, and varies with the material thickness [7,21]. The R-values per an area unit of material roofing were shown in Table 2. Thermal resistance is calculated by the ratio of the thickness of its layer and its thermal conductivity (k-value) as in Eq (1).

$$
\mathrm{R}=\frac{\Delta \mathrm{x}}{\mathrm{k}}
$$

where $\mathrm{R}$ is thermal resistance value $\left(\mathrm{m}^{2} \mathrm{~K} / \mathrm{W}\right), \mathrm{x}$ is layer thickness $(\mathrm{m})$, and $\mathrm{k}$ is thermal conductivity $(\mathrm{W} / \mathrm{m} \cdot \mathrm{K})$

The total R-value $(\Sigma \mathrm{R})$ is the sum of the Rvalues in each component of each model. The total R-values of the SF, SF-PCM, DF, and DF-PCM were at $15.42,15.48,18.32$ and $18.38 \mathrm{~m}^{2} \mathrm{~K} / \mathrm{W}$, respectively (Table 3 ). These total $\mathrm{R}$-value indicated that the DF model could increase ability to resist heat transmission than the SF model. In addition, the PCM application with the SF and DF could lead to 
Table 2 The material properties and thermal resistance value of each component.

\begin{tabular}{lccc}
\hline Material property & $\begin{array}{c}\text { Thickness } \\
\Delta \mathrm{x}(\mathrm{m})\end{array}$ & $\begin{array}{c}\text { Coefficient of thermal } \\
\text { conductivity K }(\mathrm{W} / \mathrm{m} \cdot \mathrm{K})\end{array}$ & $\begin{array}{c}\text { Thermal resistance } \\
\mathrm{R}\left(\mathrm{m}^{2} \mathrm{~K} / \mathrm{W}\right)\end{array}$ \\
\hline Fiber cement roofing sheet & $50.19 \times 10^{-3}$ & 0.390 & 0.013 \\
Phase change material & $21.50 \times 10^{-3}$ & 0.240 & 0.009 \\
Gypsum board ceiling & $30.00 \times 10^{-3}$ & 0.084 & 0.036 \\
The high reflective film & $10.00 \times 10^{-3}$ & 0.040 & 0.025 \\
Air gap between roof layers & 0.15 & 0.026 & 0.577 \\
Air of attic & $0.325,0.400$ & 0.026 & $12.500,15.385$ \\
\hline
\end{tabular}

Table 3 Total R-value ( $\Sigma \mathrm{R})$ and the R-values of each component for each testing model.

\begin{tabular}{|c|c|c|c|c|c|c|c|c|c|}
\hline \multirow{2}{*}{ Model } & \multicolumn{8}{|c|}{ Thermal resistance of each position $\mathrm{R}\left(\mathrm{m}^{2} \mathrm{~K} / \mathrm{W}\right)$} & \multirow{2}{*}{$\begin{array}{c}\Sigma \mathrm{R} \\
\left(\mathrm{m}^{2} \mathrm{~K} / \mathrm{W}\right)\end{array}$} \\
\hline & Roof 1 & Reflective film 1 & PCM & Reflective film 2 & Air $_{\text {gap-roof }}$ & Roof 2 & Air $_{\text {attic }}$ & Ceiling & \\
\hline SF & 0.013 & - & - & - & - & - & 15.385 & 0.036 & 15.42 \\
\hline SF-PCM & 0.013 & 0.025 & 0.009 & 0.025 & - & - & 15.385 & 0.036 & 15.48 \\
\hline $\mathrm{DF}$ & 0.013 & - & - & - & 0.577 & 0.013 & 12.500 & 0.036 & 18.32 \\
\hline DF-PCM & 0.013 & 0.025 & 0.009 & 0.025 & 0.577 & 0.013 & 12.500 & 0.036 & 18.38 \\
\hline
\end{tabular}

higher R-value. When considering heat transfer or the U-value of roof (calculated from the reciprocal of the total R-value in each model), the U-values of the SF, SF-PCM, DF, and DF-PCM were 64.85, 64.60, 54.59 and $54.42 \mathrm{~mW} / \mathrm{m}^{2} \cdot \mathrm{K}$, respectively.

\section{CONCLUSION}

The integration of PCM with the fiber cement roofing sheet was shown to increase thermal performance of the roof. Through the SF, SF-PCM, DF, and DF-PCM models, we found the reduction in room temperature when PCM was added. This would lead to an increasing in building energy saving and a decline in the annual peak cooling demand.

\section{Appendix A. Supplementary data}

Supplementary data associated with this article can be found at http://dx.doi.org/10.2306/ scienceasia1513-1874.2021.S017.

Acknowledgements: The authors would like to thank the Thailand Science Research and Innovation (TSRI), Faculty of Science, Naresuan University for providing financial support.

\section{REFERENCES}

1. Kamma J, Manomaiphiboon $\mathrm{K}$, Aman $\mathrm{N}$, Thongkamdee T, Chuangchote S, Bonnet S (2020) Urban heat island analysis for Bangkok: multi-scale temporal variation, associated factors, directional dependence, and cool island condition. ScienceAsia 46, 213-223.
2. Mano C, Thongtha A (2021) Enhanced thermal performance of roofing materials by integrating phase change materials to reduce energy consumption in buildings. J Renewable Mater 9, 495-506.

3. Al-Masrani SM, Al-Obaidi KM (2014) Passive cooling techniques through reflective and radiative roofs in tropical houses in Southeast Asia. Front Archit Res 3, 283-297.

4. Yang L, Yan H, Lam JC (2014) Thermal comfort and building energy consumption implications: A review. Appl Energy 115, 164-173.

5. El-Darwish I, Gomaa M (2017) Retrofitting strategy for building envelopes to achieve energy efficiency. Alexandria Eng $J$ 56, 579-589.

6. Meng E, Wang J, Yu H, Cai R, Chen Y, Zhoua B (2019) Experimental study of the thermal protection performance of the high reflectivity-phase change material (PCM) roof in summer. Build Environ 164, ID 106381.

7. Alawadhi EM, Alqallaf HJ (2011) Building roof with conical holes containing PCM to reduce the cooling load: Numerical study. Energy Convers Manage 52, 2958-2964.

8. Mussa HM, Salih TWM (2020) Thermal insulation performance of wood-plastic composite panels as alternative to alucobond cladding sheets for building. $J$ Eng Sustainable Dev 24, 425-433.

9. Darsana P, Abraham R, Joseph A, Jasheela A, Binuraj PRB, Sarma J (2016) Development of coir-fibre cement composite roofing tiles. Procedia Technol 24, 169-178.

10. Ismail AI, Kunle AA, Ronke OY (2018) Energy efficient buildings in tropical climate through passive techniques-an overview. J Environ Earth Sci 8, 45-49. 
11. Chung MH, Park JC (2017) An experimental study on the thermal performance of phase-change material and wood-plastic composites for building roofs. Energies 10, ID 195.

12. Wang X, Yu H, Li L, Zhao M (2016) Experimental assessment on the use of phase change materials (PCMs)-bricks in the exterior wall of a full-scale room. Energy Convers Manage 120, 81-89.

13. Zhong K, Li S, Sun G, Li S, Zhang X (2015) Simulation study on dynamic heat transfer performance of PCM-filled glass window with different thermophysical parameters of phase change material. Energy Build 106, 87-95.

14. Lu S, Chen Y, Liu S, Kong X (2016) Experimental research on a novel energy efficiency roof coupled with PCM and cool materials. Energy Build 127, 159-169.

15. Guichard S, Miranville F, Bigot D, Boyer H (2014) A thermal model for phase change materials in a building roof for a tropical and humid climate: Model description and elements of validation. Energy Build 70, 71-80.
16. Jayalath A, Aye L, Mendis P, Ngo T (2016) Effects of phase change material roof layers on thermal performance of a residential building in Melbourne and Sydney. Energy Build 121, 152-158.

17. Kośny J, Biswas K, Miller W, Kriner S (2012) Field thermal performance of naturally ventilated solar roof with PCM heat sink. Sol Energy 86, 2504-2514.

18. Jin X, Zhang X (2011) Thermal analysis of a double layer phase change material floor. Appl Therm Eng 31, 1576-1581.

19. Stavrakakis GM, Androutsopoulos AV, Vyörykkä J (2016) Experimental and numerical assessment of cool-roof impact on thermal and energy performance of a school building in Greece. Energy Build 130, 64-84.

20. Alqallaf HJ, Alawadhi EM (2013) Concrete roof with cylindrical holes containing PCM to reduce the heat gain. Energy Build 61, 73-80.

21. Chou HM, Chen CR, Nguyen VL (2013) A new design of metal-sheet cool roof using PCM. Energy Build 57, 42-50. 


\section{Appendix A. Supplementary data}

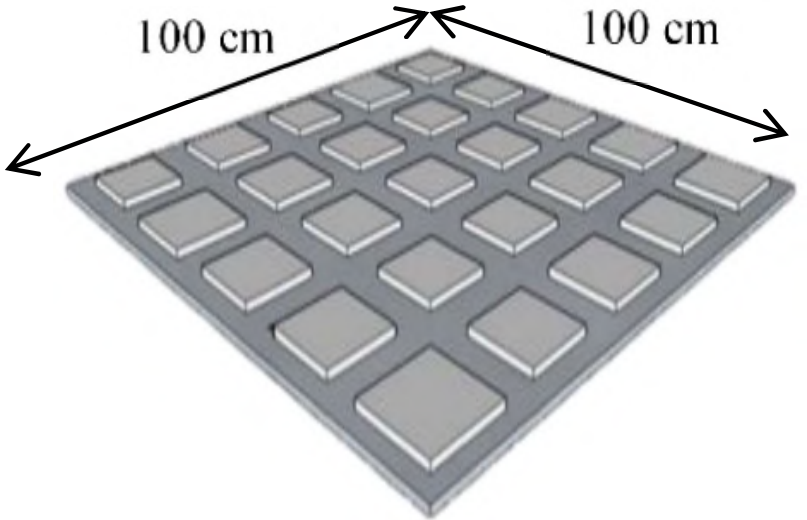

(a)

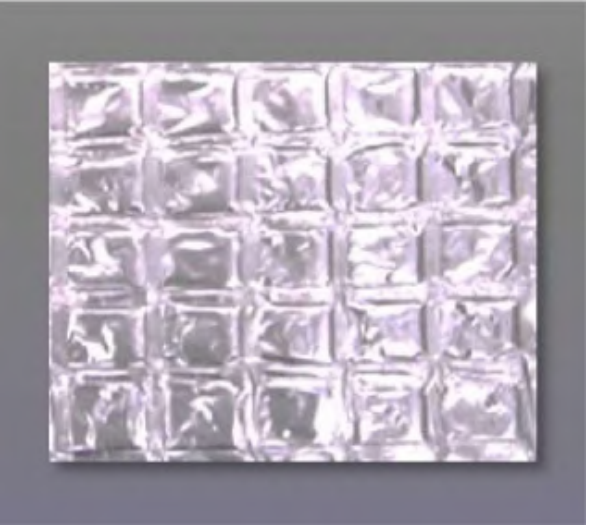

(b)

Fig. S1 (a) Dimensions of the used PCM layer for testing, (b) PCM layer samples integrating into the sheet metal roof.
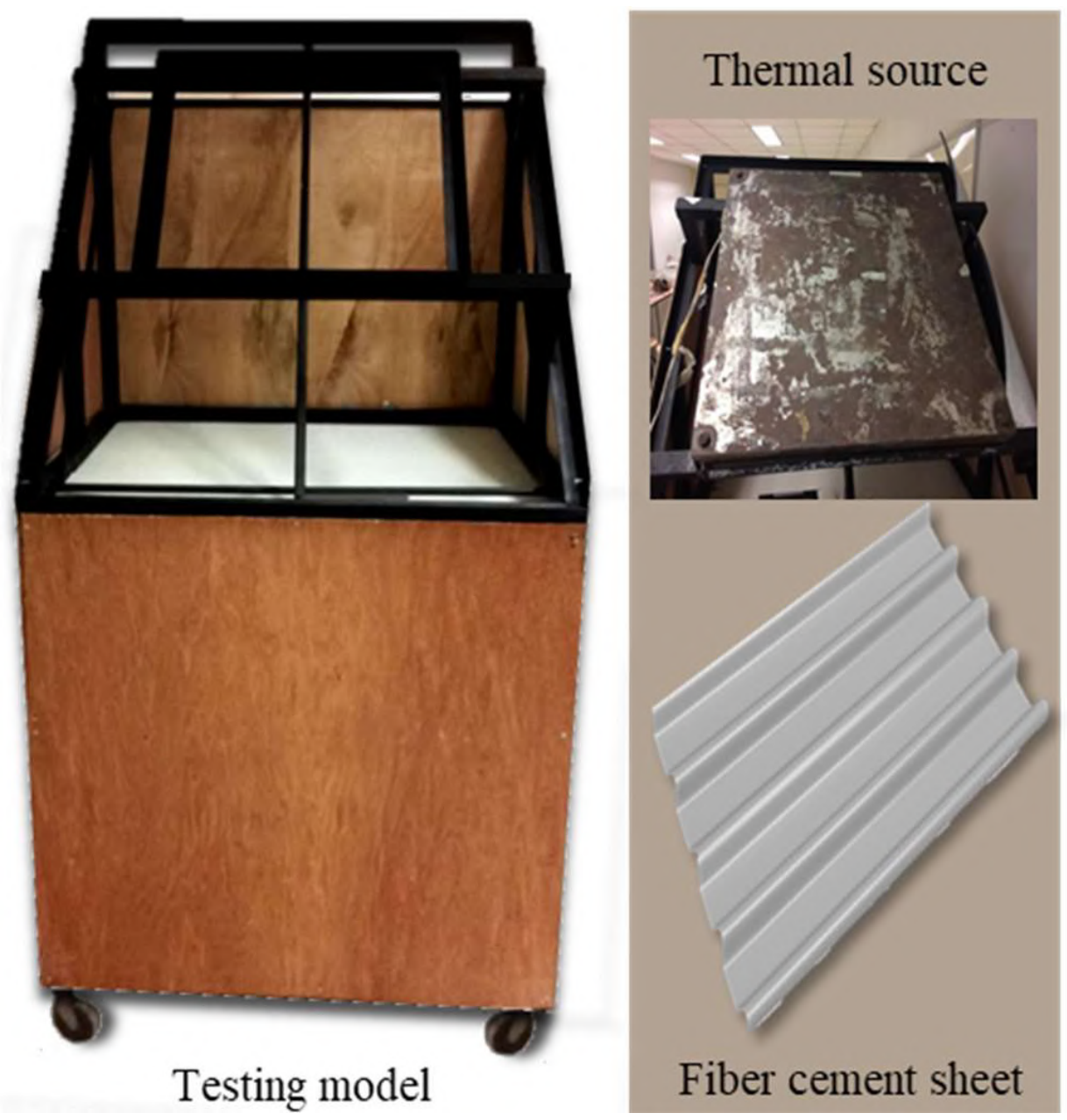

Fig. S2 The actual experimental setup for PCM application with the fiber cement sheet. 